\title{
GOVERNMENT CREDIT GUARANTEE (GCG) FOR THE IMPROVEMENT OF PEOPLE AT THE BOTTOM OF THE ECONOMIC PYRAMID
}

\author{
SUBKHAN \\ International Islamic University Malaysia (IIUM), Gombak, Kuala Lumpur, Malaysia
}

\begin{abstract}
The main objective of this study is to measure the impact of Government Credit Guarantee (GCG) scheme on household poverty alleviation. This study employed a cross-sectional design with purposive random sampling method to examine whether participation in GCG programs improves the hardcore poor households quality of life. To analyze the impact of GCG scheme on household poverty reduction, this study uses logistic regression model. The findings confirmed that households participating in GCG programs tend to have higher probability in reducing their poverty condition compared with those who have no access to GCG programs. The reduction in household poverty can be described by the improvement in their monthly income, improvement in monthly food expenditures, and improvement in monthly non-food expenditure. Therefore, Indonesian Government should review, re-organize and improve the GCG programs and policies in order to increase the outreach and improve client's ability to receive higher amount of loan through GCG scheme.
\end{abstract}

\section{A. Introduction}

Micro Small and Medium Enterprises (MSMEs) play an important role in the Indonesian economy. MSMEs are able to provide jobs and drive the economy, especially the primary and secondary sectors so as to improve household income. For low income or poor people in rural areas, MSMEs are very important since these enterprises have been an important engine for the development of local economy and community (Tambunan, 2008). In 2012, MSMEs contributed 58.1 percent to GDP, 97.2 percent to the creation of employment opportunities, and 14.1 percent to the export revenue (Ministry of Cooperative and MSEs, 2014). This indicates MSMEs have important role in stimulating economic growth, creating jobs, and strengthening export structure as well as accelerating poverty reduction (Firdausy, 2005; LIPI, 2014).

This condition is in line with the policy package issued by the Indonesian Government called the Master Plan for the Acceleration and Expansion of Poverty Reduction in Indonesia (master plan percepatan dan perluasan penurunan kemiskinan Indonesia / MP3KI). The master plan is directed through the integration and synergy of poverty alleviation programmes and adapted to the conditions of each region / area. In the implementation, this master plan is grouped into four clusters: (1) assistance and social protection for the poor in the forms of school operation assistance, cheap rice for the poor, health insurance and assistance for the fulfillment of basic needs; (2) community empowerment, a programme to encourage self-reliance in poverty 
reduction; (3) government programmes for the poor such as the procurement of low-cost housing, cheap public transportation, cheap electricity programme, and a community-based drinking water programme, and (4) Government Credit Guarantee (GCG) or commonly called Credit programme for micro, small, and medium enterprises (Kredit Usaha Rakyat/KUR).

GCG is financing scheme provided for the MSMEs that have the ability to build productive enterprises (feasible), but have limitations in meeting the requirements of the bank to get loan/financing.

According to Law No.20/ 2008, the main purpose of the Government Credit Guarantee is to accelerate the development of economic activities in the real sector, to alleviate poverty, to expand work opportunities and to improve household welfare. The detailed objectives of the KUR programme are as follows:

a. Accelerate real sector development and empower micro, small and medium enterprises and cooperatives (UMKMK).

b. Increase access to finance of MSMEs and develop their access to the financial institution.

c. As part of poverty alleviation efforts and measures to expand job opportunities.

d. Reduce income inequality among societies.

To support MSMEs, on June 8, 2007, the Indonesian Government launched the Presidential Decree No. 6/2007 on the Acceleration of Real Sector Development and MSMEs Empowerment, and lastly replaced by Presidential Decree No. 19/2015 on Financing Policy Committee for Micro Small and Medium Enterprises. One important step in the implementation of the Decree was the Credit Guarantee Programmes for MSMEs (Kredit Usaha Rakyat/KUR). The main goal of this scheme is to improve the access of MSMEs to sources of capital from formal financial institutions in order to accelerate poverty reduction, employment creation and income generation.

Since it was launched in 2007, implementation of the GCG programme has shown continued improvement. In the period from 2008 to September 2014, the number of banks participating in the programme has grown from six national banks to 33 banks ( 7 national banks and 26 regional banks). In the same period, the number of GCG beneficiaries increased nearly five-fold from 2.3 million to 11.3 million people. Meanwhile, the amount of loans disbursed through the GCG scheme increased by about 4.5 times from 11.5 trillion rupiah to 50.3 trillion rupiah. Even in 2016 and 2017 the amount of loans channelled through GCG reached 94.4 trillion rupiah and 96.7 trillion rupiah respectively. Within the period of 2010 to September 2014, the actual distribution grew by an average of $30.7 \%$ per year, while the proposed distribution only increased by an average of $16.6 \%$ per year. Not surprisingly, the realization of GCG, especially since 2011, has always exceeded the target set by the government. This is an indication that the demand from MSMEs for GCG programme is much higher than that assumed by the government.

\section{B. Statement of the Problem}

Although the number of GCG customers has been increasing significantly, the contribution of MSMEs in the Indonesian economy is still lower compared to its potential. This is reflected in two indicators. First, the number of officially registered MSMEs in Indonesia is relatively lower compared to the average number of MSMEs globally or in comparison with several ASEAN 
countries. Number of registered MSMEs in Indonesia was still less than $30 \%$ of total MSMEs, while in Vietnam and the Philippines were $87 \%$ and $98 \%$ respectively (World Bank, 2009).

Second, the productivity of MSMEs is relatively low compared to large scale businesses. This indicates that in general MSMEs are in an increasingly weak position to compete with other businesses. Some literature (Yamamoto, 2001; Adam, 2009; Bhasin and Venkataramany, 2010) indicate that the limited ability of MSMEs to expand marketing network and access of MSMEs to sources of capital, information, and technology are the basic factors that inhibit an increase in productivity of MSMEs that affect household welfare.

MSMEs often encounter obstacles to develop their potential, especially for newly established businesses and industries engaged in the service sector and are usually excluded from the banking system for several reasons. Those barriers are mainly related to the difficulty of access to financing due to the lack of tangible assets that can be pledged as collateral (Samujh et al., 2012). Green (2003) found that limited access to financing of MSMEs is mainly due to inadequate collateral, relatively high administrative cost for small value of loans, high business risk, as well as the asymmetric information. Samujh et al. (2012) identify three factors explaining the banker reluctance to provide credit to small enterprises including collateral, cost, and risk. Associated with collateral, MSMEs usually have little or no collateral and often lack of commitment to repay their loans as a consequence of the guarantee scheme provided by the government or loan guarantee corporations. Banks and microfinance instituions (MFIs) usually charge high margin of funding to people at the low income level, affecting the affordability of financing. In addition, according to Fletschner (2009), gender issue is also a concern. Men have greater access to financing than women because men are believed to be able to generate more income than women.

In the specific case of Indonesia, there is also the issue of minimum participation of borrowers in Indonesia's formal financial institutions. Approximately 80 per cent of indonesia's poor has no access to formal financial services. In general, households use banks or traditional cooperatives as medium for saving. However, for the purpose of borrowing, the informal sector (neighbours, friends, groups of societies at local level, small shops) are more commonly used. One of the major reasons why a lot of people at low income level prefer to choose friends and relatives as a source of funding rather than other informal funding alternatives in Indonesia is because other sources particularly including some professional money lenders behave like the loan sharks in terms of imposing highly exorbitant rate (Turvey, Kong, and Huo, 2010). According to World Bank (2010) there is significant imbalance in acces of financing related to geographic location, type of work, and of course, level of income. Residents living in the rural area and those working in agricultural sector generally have less access to financial services.

Another issue related to access of MSMEs on microfinance is discrimination (Mason, 2014). Research has found that some banks and MFIs tend to discriminate MSMEs based on personal biases such as gender, disability, payment ability, or to comfort with institutional goals of targeting women over men. Additionally, banks and MFIs also exercise subjectivity in deciding who should receive the loans.

MSMEs represent a core target group for fostering local economic development and contributing to poverty reduction. Therefore, easy access to microfinance especially through GCG scheme is targeted on the design and implementation of a poverty alleviation strategy that is included in welfare improvement program of Indonesian Government, which is in line with the Millennium Development Goals (MDGs) and Sustainable Development Goals (SDGs) (Vice President Secretariat, 2011). Measuring the impact of accessibility to financing through GCG scheme on 
hosehold welfare improvement is important to enhance substantial contribution to literature review since the welfare improving goals is the key of Sustainable Development Goals.

\section{Objectives of the Study}

As previously explained, that one of the main purposes of GCG programme is poverty alleviation. Poverty is defined as the condition of households or individuals when they are economically unable to access the set of goods and services needed to ensure a better life in the society. This inability is characterized by low levels of income to meet basic needs in the form of food, clothing, and housing (Feng, 2004). On the back of the issues identified in the problem statement, the general objective of this study is to examine the impact of access to GCG programme on household poverty reduction.

\section{Hypothesis}

Based on the objective of the study, to examine the influence of access to GCG programme on household poverty reduction, there are three hypotheses:

1) Access to GCG has a positive impact on household monthly income;

2) Access to GCG has a positive impact on household monthly food expenditures;

3) Access to GCG has a positive impact on household monthly non-food expenditures;

\section{E. Literature Review}

\section{Credit Guarantee}

Micro, small and medium enterprises (MSMEs) play a very important role in economic development in both the developing and developed countries through the creation of new businesses, job creation, increased productivity and poverty reduction (Green, 2003; Samujh, Twiname, \& Reutemann, 2012). In general, the advantage of MSMEs is that they are flexible businesses with simple production structure which allow them to capture market opportunities quickly. MSMEs make a major contribution to the economy in terms of job creation. However, along the way, MSMEs often encounter obstacles to develop their potential, especially for newly established businesses and industries engaged in the service sector. Those barriers are mainly related to the difficulty of access to financing due to the lack of collateral in the form of tangible assets (Samujh et al., 2012). Green (2003) found that limited access to financing of MSMEs is mainly due to inadequate collateral, relatively high administrative cost for small value of loans, high business risk as well as the asymmetric information. In addition, the difficulty of small businesses in developing countries to get access to credit is also caused by an underdeveloped financial system, the least liquidity, and lack of experience in giving the loans to small-scale businesses. Samujh et al. (2012) identified three factors explaining the banker reluctance to provide credit to small enterprises including collateral, cost, and risk. Associated with collateral, MSMEs usually have little or no collateral and often lack of commitment to repay their loans as a consequence of the guarantee scheme provided by the government or loan guarantee corporations. The absence or lack of credit history, limited number of reliable and trusted records, and the lack of credible risk assessment are also the reasons why banks are reluctant to provide debt to small companies (Kang \& Heshmati, 2008). 
The lower funding received by MSMEs compared with other advanced businesses, in the long term, may lead to declining competitiveness, diminishing productivity, less optimal utilization of entrepreneurship. All these may ultimately result in lower economic growth. To address the challenges faced by MSMEs in gaining access to financing, many countries established a loan guarantee scheme or credit guarantee scheme (CGS). O'Bryan (2010) defines CGS as a scheme in which the lenders will get the guarantee of a third party when they provide loans to borrowers with no collateral. This scheme encourages financial institutions to get involved in providing loans to MSMEs. Moreover, CGS also encourages financial institutions to provide financing to small businesses with the assurance that if the firms default the government or credit guarantee institution will refund for the portion of the debt borrowed in accordance with the agreement (Boocock and Shariff, 2005), thus CGS can help overcome the reluctance of banks to provide loans for SME (Samujh et al., 2012).

In this scheme there are three parties involved, namely: loan guarantee institution, a lender who provide lending to borrower and a borrower who does not have collateral (O'Bryan, 2010). In general, credit guarantee could help small and medium enterprises overcome their difficulties in getting the access to credit. Study conducted by Kang \& Heshmati (2008) indicates that generally, in the presence of credit guarantees, the company's performance could improve significantly. However, the guaranteed amounts have no clear impact since there are differences between contemporary and lagged impact. Therefore CGS only partly meets its objectives to enable MSMEs to obtain financing and stabilize jobs. On the other hand, using data from Korea, Kim (2004) concluded that in general there was insignificant relationship between loan guarantee and MSMEs performances.

With CGS, the risks incurred by the lenders as a result of the lack of small companies' collateral can be reduced. Beside diminishing risk of the lenders, CGS also provides better information of borrowers. The presence of CGS enables small businesses to obtain formal financing for capital and investment, thereby increasing their competitiveness and economic activities (Green, 2003). In the short term, CGS provides positive impacts on MSMEs, but in the long-term development outcomes of CGS are still unclear (Bateman \& Chang, 2009).

\section{The Objectives of Credit Guarantee Scheme}

Guarantee scheme is designed to cope with the problems faced by small and medium enterprises either at micro lever or macro level (Samujh et al., 2012). At the micro level, guarantee scheme is designed to assist borrowers and provide incentives for lenders. In assisting customers, CGS is intended to improve access for small and medium enterprises in obtaining financing, to ensure the availability of loans for small and medium enterprises, to reduce costs of borrowing as well as to encourage business formation, development and expansion. Credit Guarantee Scheme is also designed to provide incentives for lenders through many ways. These include: 1) Providing guarantees for MSMEs that are not able to provide sufficient collateral or do not have the financial records to prove their worthiness; 2) Allowing lenders to shift the risk of repayment of the loan to the credit guarantee institution; 3) Addressing the problem of asymmetric information by the involvement of the lenders in the monitoring process, risk diversification, and supporting financial institutions to provide loans for MSMEs that do not have adequate collateral.

At macro level, CGS is intended to support the achievement of national policy objectives which include: poverty reduction with the expansion of the informal sector projects, creation of jobs, reduction of unemployment rate, acceleration of economic growth and improvement of people's welfare (Kang \& Heshmati, 2008). 


\section{Dealing with Asymmetric Information}

The main reason why banks are usually not willing to give loans to MSMEs is asymmetric information. In many cases, MSMEs have difficulty in obtaining loans because they do not have a proper accounting records and the lack of collateral. This raises the uncertainty of MSMEs in obtaining returns in the future and results in a lower commitment of loan repayment (OECD, 2013). Collecting information is very challenging for the MSMEs and obtaining information about the MSMEs requires high costs. This explains why banks charge high interest rates on borrowing to cover expenses incurred. For the banks, visiting and monitoring MSMEs who receive loans need high costs, and are not economically rational if the value of the loans is small. Study conducted by Green (2003) showed that each year administration costs incurred by the Colombian Financial Institution for small loans reached 11 to 13 percent. Asymmetric information triggers adverse selection in which the probability of failure increases because of high interest rates and this condition makes lending more risky. At the end, the high administration costs and adverse selection result in credit rationing since credit will be given only based on the size of the businesses and the amount of collateral. Establishment of CGS would help overcome the problem of asymmetric information by identifying risks more accurately, therefore banks have capability to improve their policy decision (Levitsky, 1997).

\section{Decreasing Collateral requirement}

Value of collateral determines the amount of borrowing provided by banks to borrowers since collateral may reduce the risk of bad debts. If the company fails, the collateral can be used by a bank to recover part or all of the value of defaulted loans.

However, many entrepreneurs, especially small companies, do not have enough tangible assets to cover collateral requirements from the banks, and as a consequence they find difficulties to obtain financing from banks.

Banks often assume that MSMEs are high-risk borrowers. So, to reduce the risk banks offer loans to MSMEs with high interest rates or require sufficient collateral. Because MSMEs do not have enough assets as collateral, the CGS can be used as instruments to reduce high collateral requirement of the banks. If MSMEs are able to provide collateral with minimal value as requested, banks will provide loans to MSMEs with a low interest rate. However, banks typically will not raise interest above certain level in order to maintain the quality of loans. The CGS can facilitate MSMEs with insufficient collateral to obtain the access of funding from the banks (OECD, 2013).

\section{Shifting the Risk}

In developing countries, during economic crisis MSMEs are usually more vulnerable. This condition, compounded by the weakness of the creditor and the absence of collateral registration, contributes to higher risks of lending to MSMEs. CGS can help lower the risk incurred by the lender by transferring the risk of lending to institutions that provide credit guarantees. In addition, CGS also can overcome the problem of insufficient collateral and absorb the risk of the borrowers so as to secure loan repayment in the case of default.

When CGS is not designed properly, it can lead to moral hazard of borrowers. Since most of the collateral does not come from the borrowers, they might have a higher incentive to default. However, if CGS is managed precisely - for example by dividing the risk to the borrower, the lender and the guarantor - the moral hazard can be eliminated properly. 
Each country has different risk-sharing ratio. In general, the risk is shared between the credit guarantee institution and the lender depending on the level of development of financial institutions (Nigrini \& Schoombee, 2002). In Japan, all of the risk of failure will be borne by the guarantor. Hence, the lender will incur no risk at all. Meanwhile, in the United States the lender bears 10 percent of the loan in case of default, while the rest will be borne by the guarantor. In developing countries such as Indonesia and Malaysia the risk is shared between lender and guarantor with average portion of 30 percent and 70 percent respectively. Table 2.1 suggests the risk sharing responsibility between the lender and the guarantor.

Table 1: Risk Sharing

\begin{tabular}{lcc}
\hline Country & Risk Portion of Lender & Risk Portion of Guarantor \\
\hline Egypt & $50 \%$ & $50 \%$ \\
\hline Indonesia & $30 \%$ & $70 \%$ \\
\hline Malaysia & $10-30 \%$ & $70-90 \%$ \\
\hline South Africa & $20 \%$ & $80 \%$ \\
\hline United States & $10 \%$ & $90 \%$ \\
\hline Japan & $0 \%$ & $100 \%$
\end{tabular}

Source: Samujh et al. (2012)

\section{The Bottom of Economic Pyramid}

The term "people at the BOP" first came from Prahalad and Hart (2002) who explained that the world's population in tier 4 of the economic pyramid is dominated by those who have per capita income of less than $\$ 2$ per day. The characteristics of the people at the BOP are that they could not participate in the global market economy and live in rural villages or urban slums and shanytowns. Moreover, they have no legal title of their assets, no formal education, and face difficultes in obtaining credit. Bharti et al. (2014) add several characteristics of people at the BOP such as the dominance of illiteracy, poor health and unemployment. More alarmingly, people at the BOP are dominated by Muslims who live under the poverty level. Half of the global poverty resides in the Muslim world with the Muslim population constituting $24 \%$ of the total world population (Mughal, 2014).

\section{Government Credit Guarantee (GCG) Scheme in Indonesia}

The common issue faced by SMEs is inadequate access to banking sector as one of the most important sources of capital. In 2008, only 12 percent of MSMEs were able to get access to banking sector (Arsyad, 2008). Banks are reluctant to open up access to credit to MSMEs due to several considerations. First, high administrative costs (transaction costs) to select, distribute, monitor and collect payments of small-scale credit to MSMEs (Adam, 2010). Second, the high risk of bad loans (risk of loan default) because MSMEs do not have the experiences to manage credit and do not have a good financial book keeping system which create difficulties for banks to select and assess the feasibility of MSMEs (Adam, 2010; Nugroho, 2011). As a result, banks will assess the creditworthiness of the MSME's ability to provide collateral. Third, banks have operational limitations in serving small-scale loans to MSMEs because they have to follow the rules of micro-prudential banking. For example, banks will only serve customers (MSMEs) which have reserves (Nugroho, 2011).

To overcome the problem faced by MSMEs, The Indonesian Government launched policy package on credit guarantee schemes for SMEs which is called the Credit for Small Businesses 
(Kredit Usaha Rakyat / KUR). This program is expected to be a solution for SMEs, which are economically feasible but not bankable, to develop their own businesses to support poverty reduction programs. According to Retnadi (2008), the obstacles in implementing GCG programme include, among others: (1) lack of understanding on the credit guarantee scheme either by a bank officers or borrowers/customers, (2) credit disbursement cannot be done instantly because of lack of capable human resources, (3) any changes in macroeconomic conditions, such as inflation and rising interest rates, which lead to declining loan demand.

Meanwhile Sharif (2011) stated that GCG was an innovative credit scheme and highly beneficial for SMEs to support their production activities and generate income. Therefore GCG program should be maintained and developed by both the government and other stakeholders by finding out solutions to overcome the obstacles that may occur during the implementation and development.

Of the total 51.2 million business units in Indonesia, 99 percent are micro, small, and medium enterprises (MSMEs). However, the contribution of MSMEs to the Indonesian economy has not been optimal compared to potential. This indicates that the micro and small businesses do not grow and develop into a business with larger scale (World Bank, 2009). The productivity of MSMEs is very low, therefore productivity gap between MSMEs and Large Enterprises continues to widen. In general, level of competitiveness of MSMEs in the market is very low. Some literature (Yamamoto, 2001; Adam, 2009; Bhasin and Venkataramany, 2010) showed that the limited ability of MSMEs to expand the marketing network, and limited access of MSMEs to access sources of capital, information, and technology are the basic factors that inhibit the improvement of their productivity.

\section{Microcredit and Poverty Alleviation}

Quoc (2011) investigated the impact of access to formal credit on poverty reduction in Mekong, Vietnam based on the household poverty indicators like consumption on food and non-food, expenditures on education and health care, and total income. This research revealed that level of household poverty in Mekong was likely to decrease due to the access of society on formal credit. Moreover, this finding also suggested that borrowers had more opportunities to increase their expenditures on health care, education and improve total income compared to nonborrowers. Since microcredit is a potential instrument to effectively address poverty by providing financing to poor households, currently microcredit is promoted as a key development strategy for empowering poor household and reducing poverty (Okibo \& Makanga, 2014). Manandhar \& Pradhan (2005) also supported previous opinions that microfinance could help poor people overcome their poverty. Through microfince, low income households have opportunity to take advantage from the economy to improve their living standard through establishing new businesses which in turn reduce poverty.

In most countries, because of limited understanding on financial services, limited infrastructures and regulatory constraint many poor people have difficulties to access financing. Therefore, building inclusive financial system will enable those group of people to alleviate their constraint to access credit (Antipolis, 2014). This inclusive financial system will support poor people in alleviating poverty by empowering them through accessing financial services and integrating them to the economic activities.

\section{F. Research Methodology}


This study uses logistic regression model to analyze the impact of GCG scheme on household poverty alleviation. According to Hsieh and Lee (2013), logistic regression can be used to explain the relationship between a set of covariate or explanatory variables and a dichotomous response variable. This regression is well suited for testing and describing the relationship between one or more categorical or continuous predictor variables and a categorical outcome variable (Peng, Lee and Ingersoll, 2002). Mohamed (2003) and Vaessen (2000) employed the logit model to examine the relative importance of household factors in determining the probability of accessing different types of credit.

In order to understand the impact of GCG scheme on household poverty alleviation, the following variables are analyzed.

Dependent variable: household poverty reduction (HPR)

Three indicators belong to poverty reduction (HPR) include income, monthly household expenditure on food, and monthly household non-food expenditure.

Independent variables:

$H H C=$ individual household characteristics (gender (GEN), age (AGE), having salary (SALARY), head of household $(\mathrm{HOH})$, and number of dependents (DEPEND)).

$L O A N=$ Size of loan indicates the amount of credit/financing received by the customer. Higher amount of credit is expected to increase household income, hence improve household welfare.

TREAT $=$ Dummy variable for treatment is equal to 1 for households receiving GCG (Credit for Small Businesses) and 0 otherwise.

ACCESS TO GCG = TREAT $*$ LOAN

OTHLOAN = Dummy variable for other loan (financing) received by customer. This dummy variable is equal 1 for households who receive other financing and 0 otherwise.

PGRDP = Per capita Gross Regional Domestic Product for each district

$P L I \quad=$ Poverty Line Income for each district

Based on the research objectives as discussed previously, research model used in this study can be described as follow:

$$
H P R_{i j}=\alpha_{0}+\beta_{1} H_{H C}+\beta_{2}(L O A N * T R E A T)_{i j}+\beta_{3} \text { OTHLOAN }_{i j}+\beta_{5} \text { PGRDP }_{i j}+\beta_{6} P L I_{i j}+\mu_{i j}
$$

\section{G. Data}

\section{Data Source}

This study uses two sources of data namely, primary and secondary data. Primary data is obtained through a questionnaire survey and interviews with respondents. The questionnaire survey was distributed to the MSMEs in Indonesia. Secondary data is obtained from available literature including journals, books and relevant materials like statistical database and bank reports.

\section{Population and Sample}


The population in this study is MSME who receives or not receives credit. The study focuses on the Central Java (Jawa Tengah) Province since this province received the highest amount of credit form the government (GCG) compared with other provinces in Indonesia. However, there was no significant improvement in poverty alleviation in this province. Income inequality was getting worse with significant increase in Gini coefficient from 0.34 in 2007 to 0.38 in 2014. Samples are collected from five districts and two cities in this province namely, Batang District, Pekalongan District, Pemalang District, Tegal District, Brebes District, Pekalongan City, and Tegal City. These districts are chosen based on the data availability and these districts represent districts with high income inequality, high unemployment rate and slow improvement in poverty reduction.

To calculate sample size, this research follows the Creative Research System and the formula used by Israel (1992). The formula used in this research to determine the sample size is described as follow:

$n_{0}=\frac{Z^{2} p q}{e^{2}}$

where:

$\mathrm{n}_{o}=$ the sample size

$\mathrm{Z}^{2}=$ the abscissa of the normal curve that cuts off an area $\alpha$ at the tails (1- $\alpha$ equals the desired confidence level, e.g. 95 percent)

$\mathrm{e}=$ the desired level of precision

$\mathrm{p}=$ estimated proportion of an attribute that is present in the population

$\mathrm{q}=1-\mathrm{p}$

If there is a large number of population and variability in the proportion is not known, then it is assumed that $\mathrm{p}=0.5$ (maximum variability).

The criterion for sample size is non-bias and data representative. Cluster sampling is chosen in this study. Based on Krejcie and Morgan (1970), 387 samples are adequate for a population of 1 million. This study uses 785 respondents as samples.

\section{H. Data Analysis}

This study conducted a field survey to obtain information from respondents who either received GCG facilities or did not get GCG facilities. Of the total 785 questionnaires collected, as many as 739 respondents' data could be processed further, representing $94.1 \%$ of the total respondents. This survey was conducted in two cities and five districts in Central Java Province. The two cities include Pekalongan City with a response rate of $91 \%$, and Tegal City with a response rate of $84.6 \%$. Meanwhile, five districts include Batang Regency with a response rate of $90.6 \%$, Pekalongan Regency with a response rate of $96.3 \%$, Pemalang District with a response rate of $98.6 \%$, Tegal Regency with a response rate of $89.2 \%$, and Brebes Regency with $100 \%$ response rate. Response rates in each city / district are detailed in Table 2 below:

Tabel 2: Survey Response Rate 


\begin{tabular}{clccc}
\hline No & City/District & $\begin{array}{c}\text { Questionnaire } \\
\text { Distributed \& } \\
\text { Collected }\end{array}$ & $\begin{array}{c}\text { Questionnaire } \\
\text { Valid }\end{array}$ & Response Rate \\
\hline 1 & Kabupaten Batang & 128 & 116 & $90.6 \%$ \\
\hline 2 & Kabupaten Pekalongan & 216 & 208 & $96.3 \%$ \\
\hline 3 & Kab. Pemalang & 138 & 136 & $98.6 \%$ \\
\hline 4 & Kabupaten Tegal & 65 & 58 & $89.2 \%$ \\
\hline 5 & Kabupaten Brebes & 59 & 59 & $100.0 \%$ \\
\hline 6 & Kota Pekalongan & 166 & 151 & $91.0 \%$ \\
\hline 7 & Kota Tegal & 13 & 11 & $84.6 \%$ \\
\hline Total & $\mathbf{7 8 5}$ & $\mathbf{7 3 9}$ & $\mathbf{9 4 . 1 \%}$ \\
\hline
\end{tabular}

In relation to income, respondents were classified into four groups. Of these groups, 47 (6.36\%) were respondents with income below $\$ 100$ per month, $479(64.82 \%)$ were respondents with monthly income of $\$ 100-<\$ 500$, and respondents with $\$ 500-<\$ 1,500$ income $124(16.78 \%)$. A small portion of respondents $(12.04 \%)$ had income above $\$ 1,000$. The data shows that the majority of respondents have low and medium incomes. In terms of wealth, respondents were classified into three groups, namely the micro business group, the small business group, and the medium business group. Most respondents involved in small business groups $(74.56 \%)$ with total assets of more than $\$ 5,000-\$ 50,000$. The number of those classified as micro businesses with maximum total assets of \$5,000 was $148(20.03 \%)$ respondents and medium businesses with total assets of more than $\$ 50,000$ were $40(5.41 \%)$ respondents. Most respondents in this study had savings in the bank (73.48\%) while the rest did not have savings in the bank. In terms of number of dependents, more than $60 \%$ of respondents had a maximum of two dependents. While the proportion of respondents who had dependents of $3-5$ was $28.82 \%$ and the rest $(9.2 \%)$ were respondents with more than five dependents.

\section{Data Screening}

There are three main steps in data screening when conducting a multivariate analysis (Hair et al., 1995). First is missing data analysis. Second is assessing the outliers and extreme values. Third is testing collinearity and independence of residuals.

Missing data are a nuisance to researchers and primarily result from errors in data collection or data entry or from the omission of answers by respondents. According to Arundina (2015), there are several methods to overcome the missing data problems in analysis. The first alternative is deleting the cases or variables that create the problems. The second involves a situation where the missing values concentrated in only a few variables in which an entire variable is dropped from the data set. The third is calculating the means. To deal with the missing data, this study utilizes the first method namely deleting the cases or variables.

Outliers, or extreme responses, may unduly influence the outcome of any multivariate analysis. Tabachnick \& Fidell (1996) identified four reasons for the presence of an outlier. These reasons include failure to specify a missing value, the source of the data is not a member of the population that intended for sampling, incorrect data entry, and the distribution for the variable 
has a more extreme value than a normal distribution. Once outliers have been identified, there are several strategies for reducing the impact. Check the data for each case to make sure of its accuracy. If the data are accurate, consider the possibility that one variable is responsible for most of the outliers. Moreover, elimination of the variable would reduce the number of outliers. If the variable or case is not critical to the analysis, delete the variable is a good alternative (Tabachnick and Fidell, 1996).

Multicollinearity occurs when independent variables in a regression model are correlated. This correlation is a problem because independent variables should be independent. The logistic regression method cannot solve the problem of multicollinearity. If the degree of correlation between variables is high enough, it can cause problems in fitting the model and interpreting the results. Collinearity diagnostic test is used to assess the interrelationship between indicator variables. Table 3 indicates that there is no problem with multicollinearity since no variables were highly correlated. 
Table 3: Correlation Matrix

\begin{tabular}{|c|c|c|c|c|c|c|c|c|c|c|c|c|}
\hline & & GEN & AGE & EDUC & $\mathrm{HOH}$ & SAL & DEPEND & INCOME & LOAN & OTHFIN & PGRDP & PLI \\
\hline \multirow[t]{3}{*}{ GEN } & Pearson Correlation & 1.000 & -0.014 & -0.051 & 0.665 & 0.062 & -0.024 & -0.051 & -0.117 & 0.019 & 0.024 & 0.009 \\
\hline & Sig. (2-tailed) & & .696 & .169 & .000 & .090 & .511 & .170 & .001 & .611 & .515 & .817 \\
\hline & $\mathrm{N}$ & 739 & 739 & 739 & 739 & 739 & 739 & 739 & 739 & 739 & 739 & 739 \\
\hline \multirow[t]{3}{*}{ AGE } & Pearson Correlation & -0.014 & 1.000 & -0.358 & -0.230 & 0.131 & 0.139 & -0.008 & 0.032 & -0.066 & 0.106 & 0.051 \\
\hline & Sig. (2-tailed) & .696 & & .000 & .000 & .000 & .000 & .826 & .391 & .073 & .004 & .163 \\
\hline & $\mathrm{N}$ & 739 & 739 & 739 & 739 & 739 & 739 & 739 & 739 & 739 & 739 & 739 \\
\hline \multirow[t]{3}{*}{ EDUC } & Pearson Correlation & -0.051 & -0.358 & 1.000 & 0.097 & -0.254 & 0.121 & 0.114 & 0.088 & -0.070 & 0.083 & 0.045 \\
\hline & Sig. (2-tailed) & .169 & .000 & & .008 & .000 & .001 & .002 & .017 & .059 & .023 & .224 \\
\hline & $\mathrm{N}$ & 739 & 739 & 739 & 739 & 739 & 739 & 739 & 739 & 739 & 739 & 739 \\
\hline \multirow[t]{3}{*}{$\mathrm{HOH}$} & Pearson Correlation & 0.665 & -0.230 & 0.097 & 1.000 & 0.076 & -0.105 & -0.092 & -0.158 & -0.025 & 0.094 & -0.025 \\
\hline & Sig. (2-tailed) & .000 & .000 & .008 & & .039 & .004 & .012 & .000 & .499 & .011 & .490 \\
\hline & $\mathrm{N}$ & 739 & 739 & 739 & 739 & 739 & 739 & 739 & 739 & 739 & 739 & 739 \\
\hline \multirow[t]{3}{*}{ SALARY } & Pearson Correlation & 0.062 & 0.131 & -0.254 & 0.076 & 1.000 & -0.121 & -0.067 & -0.028 & 0.038 & -0.003 & 0.034 \\
\hline & Sig. (2-tailed) & .090 & .000 & .000 & .039 & & .001 & .069 & .443 & .299 & .930 & .352 \\
\hline & $\mathrm{N}$ & 739 & 739 & 739 & 739 & 739 & 739 & 739 & 739 & 739 & 739 & 739 \\
\hline \multirow[t]{3}{*}{ DEPEND } & Pearson Correlation & -0.024 & 0.139 & 0.121 & -0.105 & -0.121 & 1.000 & 0.323 & 0.209 & -0.056 & -0.044 & -0.041 \\
\hline & Sig. (2-tailed) & .511 & .000 & .001 & .004 & .001 & & .000 & .000 & .125 & .231 & .264 \\
\hline & $\mathrm{N}$ & 739 & 739 & 739 & 739 & 739 & 739 & 739 & 739 & 739 & 739 & 739 \\
\hline \multirow[t]{3}{*}{ INCOME } & Pearson Correlation & -0.051 & -0.008 & 0.114 & -0.092 & -0.067 & 0.323 & 1.000 & 0.540 & 0.076 & -0.107 & -0.124 \\
\hline & Sig. (2-tailed) & .170 & .826 & .002 & .012 & .069 & .000 & & .000 & .039 & .004 & .001 \\
\hline & $\mathrm{N}$ & 739 & 739 & 739 & 739 & 739 & 739 & 739 & 739 & 739 & 739 & 739 \\
\hline \multirow[t]{3}{*}{ LOAN } & Pearson Correlation & -0.117 & 0.032 & 0.088 & -0.158 & -0.028 & 0.209 & 0.540 & 1.000 & 0.075 & -0.121 & -0.080 \\
\hline & Sig. (2-tailed) & .001 & .391 & .017 & .000 & .443 & .000 & .000 & & .042 & .001 & .030 \\
\hline & $\mathrm{N}$ & 739 & 739 & 739 & 739 & 739 & 739 & 739 & 739 & 739 & 739 & 739 \\
\hline \multirow[t]{3}{*}{ OTHFIN } & Pearson Correlation & 0.019 & -0.066 & -0.070 & -0.025 & 0.038 & -0.056 & 0.076 & 0.075 & 1.000 & -0.136 & -0.014 \\
\hline & Sig. (2-tailed) & .611 & .073 & .059 & .499 & .299 & .125 & .039 & .042 & & .000 & .713 \\
\hline & $\mathrm{N}$ & 739 & 739 & 739 & 739 & 739 & 739 & 739 & 739 & 739 & 739 & 739 \\
\hline \multirow[t]{3}{*}{ PGRDP } & Pearson Correlation & 0.024 & 0.106 & 0.083 & 0.094 & -0.003 & -0.044 & -0.107 & -0.121 & -0.136 & 1.000 & 0.364 \\
\hline & Sig. (2-tailed) & .515 & .004 & .023 & .011 & .930 & .231 & .004 & .001 & .000 & & .000 \\
\hline & $\mathrm{N}$ & 739 & 739 & 739 & 739 & 739 & 739 & 739 & 739 & 739 & 739 & 739 \\
\hline \multirow[t]{3}{*}{ PLI } & Pearson Correlation & 0.009 & 0.051 & 0.045 & -0.025 & 0.034 & -0.041 & -0.124 & -0.080 & -0.014 & 0.364 & 1.000 \\
\hline & Sig. (2-tailed) & .817 & .163 & .224 & .490 & .352 & .264 & .001 & .030 & .713 & .000 & \\
\hline & $\mathrm{N}$ & 739 & 739 & 739 & 739 & 739 & 739 & 739 & 739 & 739 & 739 & 739 \\
\hline
\end{tabular}




\section{Impact of Access to GCG on Household Poverty Reduction}

Three indicators are used to measure household poverty reduction (HPR). These indicators include income (sales of product), food monthly expenditure, and non-food monthly expenditure. These variables will act as dependent variables which are measured by 1 if improved and 0 otherwise. Access to GCG will act as independent variable that is calculated by treatment dummy variable times size of loan.

\section{Model Fitting}

The binary logistic approach is used to measure the impact of access to GCG on household poverty reduction. There are steps involved in this approach including testing the fitness of the model using Hosmer and Lemeshow test and measuring the strength between variables in the model using the pseudo r-square. Moreover, the approach also compares the predicted and actual ratings classified by the binary logistic model. Finally, model specification is employed to test the relationship between dependent and independent variables. Table 4 shows the model fitting information of the impact of access to GCG on household poverty reduction.

Table 4: Goodness-of-fit, Pseudo r-square and Classification Accuracy

\begin{tabular}{|c|c|c|c|c|}
\hline & & Income & $\begin{array}{c}\text { Food } \\
\text { expenditure }\end{array}$ & $\begin{array}{c}\text { Non food } \\
\text { expenditure }\end{array}$ \\
\hline \multirow{3}{*}{ Hosmer and Lemeshow Test } & Chi-square & 13.537 & 3.935 & 10.368 \\
\hline & $\mathrm{df}$ & 8 & 8 & 8 \\
\hline & Sig. & 0.095 & 0.863 & 0.240 \\
\hline \multirow{3}{*}{ Model Summary } & -2 Log likelihood & 905.571 & 922.616 & 935.486 \\
\hline & Cox \& Snell R Square & 0.071 & 0.129 & 0.091 \\
\hline & Nagelkerke R Square & 0.097 & 0.172 & 0.122 \\
\hline $\begin{array}{l}\text { Overall Percentage of logistic } \\
\text { classification accuracy }\end{array}$ & & 67.7 & 64.5 & 63.9 \\
\hline
\end{tabular}

(i) Hosmer-Lemeshow test

To test the fitness of the model, Hosmer-Lemeshow test is employed. This statistical test does not have exactly a limiting chi-square distribution. The Hosmer and Lemeshow test compares the observed and fitted counts for this model. Monthly income, food expenditure, and non-food expenditure have a significant Hosmer-Lemeshow test value ( $\rho$-value $>.05)$. This indicates that the model fits. Therefore all those variables can be used for further interpretation.

(ii) Pseudo r-square

Pseudo R-Square measures the strength of the impact of independent variables on the dependent variable. In this model, the pseudo r-square indicates that the power of variables is not strong since the data use is huge and it employs cross sectional data.

(iii) Classification accuracy

The classification accuracy table will strengthen the goodness-of-fit model. Results from three variables show that values of overall classification accuracy are more than $50 \%$. Therefore, it can 
be concluded that the overall classification accuracy is satisfied because the score is more than the $50 \%$ SPSS cut-off-rate.

\section{Model Specification}

All variables for household poverty reduction are significant. To measure the impact of access to GCG on household poverty reduction, the respondents were asked questions about whether their monthly income, food expenditure and non-food expenditure improved. The specific explanations of each variable are explained below:

(i) Monthly income

The result shows a higher likelihood of people who have access to GCG influencing better monthly income compared with those who have no access to GCG. The probability of respondents who have access to GCG having improvement in monthly income is 1.020 times higher as compared with those who have no access to GCG.

Access to GCG has positive effect on income generating activity. This indicates that GCG is optimal for being utilized in productive activity. This finding confirms the hypothesis stating that access to GCG has a positive impact on monthly income.

\section{(ii) Monthly food expenditure}

The positive impact of having access to GCG on improvement in food expenditure is also found in this study. It is stated that the probability of people who have access to GCG to have improvement in monthly food expenditure is 1.031 higher than people who have no access to GCG. It can be concluded that improvement of food expenditure is higher for GCG recipients as compared with non-recipient of GCG. This result is in line with study conducted by Patel (2014) which indicated that household spending for food improved after getting access to financing compared with their expenditure before having access to financing. This finding confirms the hypothesis stating that access to GCG has a positive impact on monthly food expenditure.

(iii) Monthly non-food expenditure

The result indicates that GCG recipients are more likely to have better improvement in monthly non-food expenditure as compared with people who have no access to GCG. The probability of people who have access to GCG having better improvement in monthly non-food expenditure is 1.021 times higher than those who have no access to GCG. The finding confirms the hypothesis that access to GCG has a positive influence on monthly non-food expenditure.

Overall, access to GCG has positive impact those three variables of household poverty reduction: monthly income, monthly food expenditure, and monthly non-food expenditure. The results indicate that GCG program was launched by the government for MSMEs in order to generate income so that they can improve their food and non-food spending. The findings confirm the hypothesis stating that access to GCG has positive impact on poverty reduction. Table 5 below shows the influence of access to GCG on poverty reduction. 
Table 5: Impact of Access to GCG on Household Poverty Reduction

\begin{tabular}{|c|c|c|c|c|c|c|}
\hline \multirow{2}{*}{ Variables in the Equation } & \multicolumn{2}{|c|}{ Income } & \multicolumn{2}{|c|}{ Food expenditure } & \multicolumn{2}{|c|}{ Non food expenditure } \\
\hline & $\mathrm{B}$ & $\operatorname{Exp}(\mathrm{B})$ & $\mathrm{B}$ & $\operatorname{Exp}(\mathrm{B})$ & $\mathrm{B}$ & $\operatorname{Exp}(\mathrm{B})$ \\
\hline Gender (GEN) & -0.296 & 0.744 & 0.128 & 1.136 & -0.180 & 0.835 \\
\hline Education Level: elementery (0-6 yr school) (EDUC01) & 0.321 & 1.378 & 0.466 & 1.594 & -0.187 & 0.830 \\
\hline Education Level: junior high school (7-9 yr school) (EDUC02) & 0.244 & 1.277 & 0.271 & 1.311 & -0.276 & 0.759 \\
\hline Education Level: senior high school (10-12 yr school) (EDUC03) & -0.032 & 0.968 & 0.032 & 1.033 & -0.282 & 0.755 \\
\hline Having Salary (SALARY) & -0.004 & 0.996 & $-0.672 * * *$ & 0.511 & $-0.797 * * *$ & 0.451 \\
\hline Age: under 30 yrs (AGE01) & 0.161 & 1.175 & -0.023 & 0.977 & -0.316 & 0.729 \\
\hline Age: 30 - 40 yrs (AGE02) & -0.220 & 0.803 & 0.066 & 1.069 & -0.071 & 0.931 \\
\hline Age: more than 40 - 50 yrs (AGE03) & -0.164 & 0.849 & 0.060 & 1.062 & -0.100 & 0.905 \\
\hline Monthly income: under \$100 (INCOME01) & $-0.808 *$ & 0.446 & $0.912 * *$ & 2.490 & 0.019 & 1.019 \\
\hline Monthly income: \$101 - \$500 (INCOME02) & -0.265 & 0.767 & $1.419 * * *$ & 4.131 & $0.548 *$ & 1.729 \\
\hline Monthly income: \$501 - \$1,000 (INCOME03) & -0.092 & 0.912 & $0.770 * *$ & 2.160 & 0.478 & 1.613 \\
\hline Number of dependents: 0 - 2 (DEPEND01) & -0.360 & 0.698 & -0.319 & 0.727 & 0.033 & 1.034 \\
\hline Number of dependents: 3 - 5 (DEPEND02) & -0.215 & 0.807 & $-0.663 * *$ & 0.515 & -0.190 & 0.827 \\
\hline Head of household (HOH) & 0.225 & 1.253 & -0.186 & 0.830 & 0.064 & 1.066 \\
\hline Other financing (OTHFIN) & 0.405 & 1.499 & 0.367 & 1.444 & $0.615 * *$ & 1.849 \\
\hline Percapita Gross Regional Domestic Product (in $\$ 1,000$ ) (PGRDP) & $1.025 * * *$ & 2.788 & $0.597 * * *$ & 1.817 & $0.828 * * *$ & 2.288 \\
\hline Poverty Line Income (\$) (PLI) & -0.020 & 0.981 & 0.011 & 1.011 & -0.023 & 0.978 \\
\hline Receiving KUR (TREAT) & $-0.477 *$ & 0.620 & $-0.866 * * *$ & 0.421 & $-0.482 * *$ & 0.618 \\
\hline Islamic banks (ISBANK) & 0.628 & 1.874 & 0.451 & 1.571 & $-1.996 *$ & 0.136 \\
\hline Access to Islamic banks (ISBANK*LOAN) & -0.044 & 0.957 & 0.015 & 1.015 & $0.101 *$ & 1.106 \\
\hline Access to KUR (LOAN*TREAT) & $0.020 * *$ & 1.020 & $0.031 * * *$ & 1.031 & $0.021 * * *$ & 1.021 \\
\hline Constant & $-1.349 *$ & 0.260 & $-2.023 * *$ & 0.132 & -1.037 & 0.355 \\
\hline
\end{tabular}

Notes:

a. The control variable are gender, education level, having salary, age, monthly income, number of dependents, head of household, other financing, per capita gross regional domestic product, and poverty line income

b. The reference category for each dependent variable is improvement in monthly income; improvement in monthly food expenditure; improvement in monthly nonfood expenditure

c. The reference category for access is having access to KUR

d. $(* * *)$ indicates significant at 1 percent $(* *)$ indicates significant at 5 percent; $(*)$ indicates significant at 10 percent 


\section{Conclusion and Recommendation}

Micro, Small and Medium Enterprises (MSMEs) often encounter obstacles to develop their potential, especially for newly established businesses and industries engaged in the service sector and are usually excluded from the banking system for several reasons. Those barriers are mainly related to the difficulty of access to financing due to the lack of tangible assets that can be pledged as collateral. To deal with these difficulties, the Indonesian Government Indonesian launched the Presidential Decree on the Acceleration of Real Sector Development and MSMEs Empowerment. One important step in the implementation of the Decree was the Credit Guarantee Programmes for MSMEs (Kredit Usaha Rakyat/KUR). The main goal of this scheme is to improve the access of MSMEs to sources of capital from formal financial institutions in order to accelerate poverty reduction, employment creation and income generation.

This study investigates the relationship between Government Credit Guarantee (GCG) scheme and household poverty reduction in Central Java. Relevant literatures were reviewed for the study. To guide the study, three hypotheses were developed. They were used to measure the main variables of the study. This study conducted a field survey to obtain information from respondents who either received GCG facilities or did not get GCG facilities. Of the total 785 questionnaires collected, as many as 739 respondents' data could be processed further, representing $94.1 \%$ of the total respondents.

To analyze the data generated, the logistic regression model was used. The analysis of the data revealed that there is a significant relationship between GCG programs and household monthly income, monthly food expenditure and monthly non-food expenditure. The conclusion drawn from this study therefore was that microfinance channeled through GCG scheme positively affects the reduction on household poverty.

Therefore, the following recommendations were provided to stimulate the use of microfinance channeled through GCG scheme as a poverty reduction strategy in modern societies:

a. The Indonesian government through designated financial institutions (banks) should continue to run the GCG program in accordance with the government's plan. However, the government needs to update the MSMEs data to ensure that KUR is used according to the objectives of the KUR program.

b. For MSME entrepreneurs, the GCG program should be used for productive businesses, not for consumption needs, so as to provide maximum results.

c. Financial institutions distributing financing through GCG scheme should conduct monitoring on their clients monthly sales, monthly profit, monthly food expenditure, monthly non-food expenditure, monthly medical expenditure and monthly education expenditure. Through controlling these variables, banks have participated in eradicating poverty.

d. In the future, financial institutions should not only distribute financing but also provide education and training program for their officers and MSMEs. 


\section{BIBLIOGRAPHY}

Adam, L. (2009). The Economic Role of Interfirm Networks in the Development of SM. Lambert Academic Publishing. Herstellung.

Adam, L. (2010). "The Role of SMEs in the Indonesia Industrialization." Economic and Finance in Indonesia. 45 (1):15-30.

Antipolis, N. (2014). Microfinance: A powerful tool for human capital formation in Africa African Development Bank Microfinance : A powerful tool for human development in, (October 2015). http://doi.org/10.13140/2.1.4979.8082

Arundina, T. (2015). Asset-based sukuk rating prediction: Towards building statistical and data mining models. International Islamic University of Malaysia.

Bhasin, B.B., and Venkataramany, S. 2011. "Globalization of Entrepreneurship: Policy Consideration for SME Development in Indonesia." International Business and Economic Research Journal, Vol. 9 No.4:95-103.

Boocock, G., \& Shariff, M. N. M. (2005). Measuring the effectiveness of credit guarantee schemes. International Small Business Journal, 23(4), 427-454.

Feng, Juan (2014). Relative versus absolute poverty headcount ratios: the full breakdown. World Bank.

Firdausy, C. 2005. "Roles, Problems and Policies of the Indonesian Small and Medium Enterprises in Globalization." In Globalization and World Economic Policies: Effect and Policies Responses of Nations and their Grouping, edit by Tisdell, C., 249-272. Serial Publication, New Delhi.

Fletschner, D. (2009). Rural women's access to credit: Market imperfections and intrahousehold dynamics. World Development, 37(3), 618-631. doi:10.1016/j.worlddev.2008.08.005.

Green, A. (2003). Credit Guarantee Schemes for Small Enterprises: An Effective Instrument to Promote Private Sector-Led Growth? UNIDO Working Paper (No. 10).

Hair, J. F, et al. (1995). Multivariate Data Analysis (3rd ed). New York: Macmillan Publishing Company.

Hsieh, S. H., Li, C. S., \& Lee, S. M. (2013). Logistic regression with outcome and covariates missing separately or simultaneously. Computational Statistics and Data Analysis, 66, 32-54. doi:10.1016/j.csda.2013.03.007

Israel, Glenn D. (1992). Determining Sample Size. This document is Fact Sheet PEOD-6, a series of the Program Evaluation and Organizational Development, Florida Cooperative Extension Service, Institute of Food and Agricultural Sciences, University of Florida. Publication date: November 1992.

Kang, J. W., \& Heshmati, A. (2008). Effect of credit guarantee policy on survival and performance of SMEs in Republic of Korea. Small Business Economics, 31(4), 445462.

Kim, H. W. (2004). Effect of policy loan on SMEs. Korea Development Institute (in Korean). Law Number 20 Year 2008. Micro Small And Medium Enterprises.

Levitsky. J.,(1997); Credit guarantee schemes for SMEs an international review, Small Enterprise Development, No 2 June 1997.

Mughal, Z. (2014). Poverty in Muslim world is rapidly increasing. Humanomics (Vol. 29). Retrieved from http://www.alhudacibe.com/imhd/news22.php

Nigrini, M., \& Schoombee, A. (2002). Credit guarantee schemes as an instrument to promote access to finance for small and medium enterprises: an analysis of Khula Enterprise Finance Ltd's individual credit guarantee scheme. Development Southern Africa, 
19(5), 735-750.

Nugroho, A.E. (2011). Microfinance Development in Indonesia Market Segmentation, Social Capital and Welfare Outreach to the Poor in Rural Java. Lambert Academic Publishing. Herstellung

O'Bryan, W. E. (2010). An analysis of small business loan guarantee funds. Nebraska.

OECD. (2013). Facilitating access to finance, Discussion Paper on Credit Guarantee Schemes.

Okibo, B. W., \& Makanga, N. (2014). Effects of micro finance institutions on poverty reduction in Kenya. International Journal of Current Research and Academic Review, 2(2), 76-95.

Peng, C. J., Lee, K. L., \& Ingersoll, G. M. (2002). An introduction to logistic regression analysis and reporting. The Journal of Educational Research but, 2(1), 3-14.

Prahalad, C. K., \& Hart, S. L. (2002). The fortune at the Bottom of the Pyramid. Booz Allen Hamilton Inc.

Quoc, D. V. (2011). Are households' poverty levels in Mekong Delta of Vietnam affected by access to credit?, (March). Retrieved from http://mpra.ub.uni-muenchen.de/35412/

Retnadi, D. (2008). Kredit Usaha Rakyat: Harapan dan Tantangan (Credit for Microbusiness: Expectation and Challenge). Economic Review, 212 (Juni).

Samujh, R. H., Twiname, L., \& Reutemann, J. (2012). Credit guarantee schemes supporting small enterprise development: A review. Asian Journal of Business and Accounting, $5(2), 21-40$. Gre

Tambunan, Tulu (2008). Development of SME in ASEAN with Reference to Indonesia and Thailand. Chulalongkorn Journal of Economics 20(1), April 2008: 53-83

Turvey, C. G., Kong, R., \& Huo, X. (2010). Borrowing amongst friends: the economics of informal credit in rural China. China Agricultural Economic Review, 2(2), 133-147. doi:10.1108/17561371011044261

Vice President Secretariat (2011). National Strategy for Financial Inclusion, Fostering Economic Growth and Accelerating Poverty Reduction.

World Bank (2010). Improving Access to Financial Services in Indonesia, April 2010

Yamamoto, I. 2001. "The Dynamism of Small and Medium Enterprise and Inter-Firm Linkage in Indonesia." Nippon Vol. 5 No. 1: 1-23. 